\title{
OPTIMASI PLAZA TOL DENGAN MENGGUNAKAN MIXED INTEGER NON-LINEAR PROGRAMMING
}

\author{
BERNY P. TOMASOUW ${ }^{1}$, FRANCIS Y. RUMLAWANG ${ }^{2}$ \\ ${ }^{1,2}$ Staf Jurusan Matematika FMIPA UNPATTI \\ Jl. Ir. M. Putuhena, Kampus Unpatti, Poka-Ambon \\ e-mail: bernypebo@yahoo.co.id
}

\begin{abstract}
ABSTRAK
Bagian yang cukup penting dalam sistem jalan tol adalah plaza tol yang merupakan tempat pelayanan dan pembayaran sebelum masuk tol. Plaza tol biasanya terdiri dari beberapa jalur sehingga memudahkan proses pembayaran dan pelayanan. Pengelola plaza tol harus memberikan pelayanan yang terbaik kepada pengguna jalan tol, sehingga salah satu masalah yang dihadapi adalah bagaimana meminimumkan waktu tunggu dan biaya operasional. Penelitian ini bertujuan untuk mendesain model optimasi plaza tol dengan menggunakan Mixed Integer Non Linier Programming (MINLP). Dari hasil yang diperoleh dapat ditentukan kombinasi yang tepat dari berbagai tipe jalur agar penggunaan masingmasing jalur optimal sehingga bisa meminimalkan waktu tunggu dan biaya operasional tiap jalur.
\end{abstract}

Kata kunci: Jalan tol, Mixed Integer Non Linier Programming, optimasi, plaza tol.

\section{PENDAHULUAN}

Jalan tol (di Indonesia disebut juga sebagai jalan bebas hambatan) adalah suatu jalan alternatif untuk mengatasi kemacetan lalu lintas ataupun untuk mempersingkat jarak dari satu tempat ke tempat lain. Untuk menikmatinya, para pengguna jalan tol harus membayar sesuai tarif yang berlaku. Penetapan tarif biasanya didasarkan pada golongan kendaraan dan panjangnya rute yang dilalui. Bagian yang cukup penting dalam sistem jalan tol adalah plaza tol yang merupakan tempat pelayanan dan pembayaran sebelum masuk tol.

Plaza tol terdiri dari beberapa jalur sehingga memudahkan proses pembayaran dan pelayanan. Secara umum terdapat 3 tipe jalur pada plaza tol yang dibagi menurut sistem pembayarannya, yakni :

1). Tipe manual

Sistem pembayaran pada jalur tipe ini dilayani oleh petugas dan dilakukan secara manual.

2). Tipe ACM

Sistem pembayarannya pada jalur tipe ini dilakukan dengan bantuan mesin pembayaran seperti dengan kartu kredit, namun masih tetap diawasi oleh petugas.

3). Tipe ETC (Electronic Toll system)

Sistem pembayaran pada jalur tipe ini murni sepenuhnya secara elektonik tanpa ada petugas. Tipe jalur ini biasa ditemukan pada negara-negara yang sudah maju dan biasa dipakai oleh pengguna yang sering melewati tol. Setiap pengguna jalur ini harus membuat kartu keanggotaan dan akan diberikan alat pengenal pada kendaraannya.

Tipe-tipe jalur di atas memiliki biaya dan selang waktu tunggu masuk tol yang berbeda-beda. Jelas bahwa tipe ETC memiliki biaya yang tertinggi namun selang waktu tunggunya sangat singkat, kemudian diikuti oleh tipe Gabungan, tipe ACM dan tipe manual. Dengan alasan biaya masuk maka para pengguna jalan tol umumnya memilih masuk jalur tipe manual, walaupun mereka harus lama mengantri.

Pengelola plaza tol harus memberikan pelayanan yang terbaik kepada pengguna jalan tol, sehingga salah satu masalah yang dihadapi adalah bagaimana meminimumkan waktu tunggu dan meminimukan biaya operasional. Sebagai contoh jika pada jalur tipe manual terjadi antrian yang sangat panjang sedangkan pada jalur tipe ACM terjadi kekosongan maka pengelola plaza tol mengambil keputusan untuk menukar jalur tipe ACM menjadi tipe manual sehingga dapat mengatasi masalah antrian yang panjang.

Dalam penelitian ini akan ditentukan kombinasi yang tepat dari berbagai tipe jalur agar penggunaan masing- 
masing jalur optimal sehingga bisa meminimalkan waktu tunggu dan biaya operasional tiap jalur.

\section{TINJAUAN PUSTAKA}

Dalam bukunya yang berjudul "Introduction to Queueing Theory", Cooper, R. B. (1981) membahas teori sistem antrian M/G/1. Teori ini dapat digunakan dalam menentukan sistem antrian pada plaza tol khususnya panjang antrian kendaraan.

Selanjutnya, dalam penelitiannya yang berjudul "The Toll Plaza Optimization Problem: Design, Operations, and Strategies", Kim, S. (2009) membuat model optimasi plaza tol dengan menggunakan teori sistem antrian $\mathrm{M} / \mathrm{G} / 1$. Salah satu bagian yang dioptimalkan dari model ini adalah jumlah jalur yang dalam hal ini harus berupa bilangan bulat. Oleh karena itu, dalam penelitian ini akan digunakan Mixed Integer Non-Linear Programming untuk memperoleh jumlah jalur yang optimal dari model optimasi plaza tol tersebut

\section{Mixed Integer Non-Linier Programming (MINLP)}

Mixed integer non-linier programming merupakan gabungan antara mixed integer linier programming (MILP) dengan non-linier programming (NLP). Bentuk umum model MINLP adalah sebagai berikut

dengan kendala

$$
\text { Min } f(x, y)
$$

$$
\begin{aligned}
& g(x, y) \leq 0 . \\
& x \in X . \\
& y \in Y \text { integer. }
\end{aligned}
$$

Pada MINLP, fungsi objektif atau fungsi kendalanya dapat berupa fungsi non-linier.

\section{HASIL DAN PEMBAHASAN}

\section{Model Optimasi Plaza Tol dengan MINLP}

Untuk mempermudah penurunan model optimasi plaza tol dengan MINLP maka di berikan beberapa notasi penunjang sebagai berikut :

\begin{tabular}{|c|l|}
\hline Notasi & \multicolumn{1}{|c|}{ Arti } \\
\hline $\boldsymbol{N}$ & $\begin{array}{l}\text { Jumlah keseluruhan jalur (kapasitas } \\
\text { plaza tol). }\end{array}$ \\
\hline $\boldsymbol{K}$ & Jumlah tipe jalur. \\
\hline $\boldsymbol{n}_{\mathbf{i}}$ & Jumlah jalur tipe $i$ yang dibuka. \\
\hline $\boldsymbol{b}_{\mathbf{i}}$ & $\begin{array}{l}\text { Jumlah minimum jalur tipe i yang } \\
\text { dibuka. }\end{array}$ \\
\hline $\boldsymbol{l}_{\mathbf{i}}$ & $\begin{array}{l}\text { Batas bawah jumlah jalur tipe i yang } \\
\text { dibuka. }\end{array}$ \\
\hline $\boldsymbol{U}_{\mathbf{i}}$ & $\begin{array}{l}\text { Batas atas jumlah jalur tipe i yang } \\
\text { dibuka. }\end{array}$ \\
\hline $\boldsymbol{\lambda}$ & $\begin{array}{l}\text { Total rata-rata kedatangan kendaraan } \\
\text { pada plaza tol (per satuan waktu). }\end{array}$ \\
\hline $\boldsymbol{\lambda}_{\mathbf{i}}$ & $\begin{array}{l}\text { Rata-rata jumlah kendaraan yang } \\
\text { masuk jalur tipe i. }\end{array}$ \\
\hline $\boldsymbol{\mu}_{\mathbf{i}}$ & $\begin{array}{l}\text { Rata-rata durasi pelayanan pada jalur } \\
\text { tipe i (per satuan waktu). }\end{array}$ \\
\hline
\end{tabular}

\begin{tabular}{|c|l|}
\hline $\boldsymbol{\sigma}_{\mathbf{i}}$ & $\begin{array}{l}\text { Standar deviasi durasi pelayanan } \\
\text { pada jalur tipe i. }\end{array}$ \\
\hline $\boldsymbol{L}_{\mathbf{i}}$ & $\begin{array}{l}\text { Rata-rata jumlah kendaraan yang } \\
\text { antri pada jalur tipe i. }\end{array}$ \\
\hline $\boldsymbol{w}_{\mathbf{i}}$ & $\begin{array}{l}\text { Rata-rata waktu tunggu kendaraan } \\
\text { pada jalur tipe i. }\end{array}$ \\
\hline $\boldsymbol{s}_{\mathbf{i}}$ & $\begin{array}{l}\text { Waktu standar pelayanan pada jalur } \\
\text { tipe i. }\end{array}$ \\
\hline $\boldsymbol{c}_{\mathbf{i}}$ & $\begin{array}{l}\text { Rata-rata biaya operasional pada jalur } \\
\text { tipe i. }\end{array}$ \\
\hline $\boldsymbol{d}$ & $\begin{array}{l}\text { Rata-rata nilai waktu dari pengguna } \\
\text { yang berada dalam antrian. }\end{array}$ \\
\hline $\mathbf{C}_{\mathbf{o}}$ & $\begin{array}{l}\text { Total biaya operasional plaza tol (per } \\
\text { satuan waktu). }\end{array}$ \\
\hline $\mathbf{C}_{\mathbf{w}}$ & $\begin{array}{l}\text { Total biaya tunggu-pengguna pada } \\
\text { plaza tol (per satuan waktu). }\end{array}$ \\
\hline $\boldsymbol{Z}$ & $\begin{array}{l}\text { Jumlah total biaya operasi dan biaya } \\
\text { tunggu-pengguna. }\end{array}$ \\
\hline
\end{tabular}

\section{Penurunan Fungsi Kendala}

a. Kapasitas Plaza Tol

Agar plaza tol tetap dapat melakukan pelayan dengan baik walaupun jumlah kendaraan yang akan masuk jalan tol meningkat maka rata-rata kedatangan kendaraan harus tetap kurang dari rata-rata waktu pelayanan pada setiap jalur. Sehingga diperoleh kendala

$$
\frac{\lambda_{i}}{n_{i}} \leq \mu_{i}, \forall i \in K .
$$

b. Batas Minimum Dan Maksimum Jalur Yang Dibuka Agar jumlah jalur yang dibuka tidak kurang dari kebutuhan (bisa menyebabkan bertumpuknya kendaraan) dan juga tidak melebihi kebutuhan (bisa menyebabkan naiknya biaya operasional) maka diperoleh kendala

$n_{i} \geq l_{i}, \forall i \in K$ dan $n_{i} \leq u_{i}, \forall i \in K$

c. Total keseluruhan jalur yang dibuka

Karena plaza tol hanya memuat $N$ jalur maka diperoleh

$$
\begin{aligned}
& \text { 1). } \sum_{k=1}^{K} n_{i} \leq N \text { untuk off-peak hours. } \\
& \text { 2). } \sum_{k=1}^{K} n_{i}=N \text { untuk peak hours. }
\end{aligned}
$$

d. Lamanya waktu antrian

Dalam teori antrian, panjang antrian dirumuskan oleh Pollaczek-Khintchine sebagai

$$
L_{i}=\frac{\lambda_{i}^{2}\left(\mu_{i}^{2} \sigma_{i}^{2}+1\right)}{2 n_{i}^{2} \mu_{i}\left(\mu_{i}-\frac{\lambda_{i}}{n_{i}}\right)} .
$$

Sehingga diperoleh kendala untuk rata-rata waktu tunggu kendaraan dalam antrian pada jalur tipe i yakni

$$
w_{i}=\frac{L_{i}}{\left(\frac{\lambda_{i}}{n_{i}}\right)}=\frac{\lambda_{i}\left(\mu_{i}^{2} \sigma_{i}^{2}+1\right)}{2 n_{i} \mu_{i}\left(\mu_{i}-\frac{\lambda_{i}}{n_{i}}\right)}, \forall i \in K .
$$

Selain itu rata-rata waktu tunggu kendaraan harus kurang dari waktu standar pelayanan setiap jalur tipe i sehingga diperoleh kendala

$$
w_{i} \leq s_{i}, \forall i \in K \text {. }
$$




\section{e. Fungsi Tujuan}

Karena pengelola ingin meminimalkan biaya operasional sekaligus waktu tunggu pengguna maka fungsi tujuannya berupa

$$
\text { Min } Z=\sum_{k=1}^{K}\left(c_{i} n_{i}+d \lambda_{i} w_{i}\right) \text {. }
$$

Secara lengkap, persamaan (1)-(8) merupakan model MINLP untuk optimasi plaza tol dapat disajikan sebagai berikut:

* Pada saat off-peak hours

Min $Z=\sum_{k=1}^{K}\left(c_{i} n_{i}+d \lambda_{i} w_{i}\right)$.

dengan kendala

$\frac{\lambda_{i}}{n_{i}} \leq \mu_{i}, \forall i \in K$.

$n_{i} \geq l_{i}, \forall i \in K$.

$n_{i} \leq u_{i}, \forall i \in K$.

$\sum_{k=1}^{K} n_{i} \leq N$

$w_{i}=\frac{\lambda_{i}\left(\mu_{i}^{2} \sigma_{i}^{2}+1\right)}{2 n_{i} \mu_{i}\left(\mu_{i}-\frac{\lambda_{i}}{n_{i}}\right)}, \forall i \in K$.

$w_{i} \leq s_{i}, \forall i \in K$.

$n_{i} \in \mathbb{N}, \forall i \in K$

$w_{i} \geq 0, \forall i \in K$

\section{Pada saat peak hours}

$$
\begin{aligned}
& \quad \operatorname{Min} Z=\sum_{k=1}^{K}\left(c_{i} n_{i}+d \lambda_{i} w_{i}\right) . \\
& \frac{\lambda_{i}}{n_{i}} \leq \mu_{i}, \forall i \in K . \\
& n_{i} \geq l_{i}, \forall i \in K . \\
& n_{i} \leq u_{i}, \forall i \in K . \\
& \sum_{k=1}^{K} n_{i}=N . \\
& w_{i}=\frac{\lambda_{i}\left(\mu_{i}^{2} \sigma_{i}^{2}+1\right)}{\quad 2 n_{i} \mu_{i}\left(\mu_{i}-\frac{\lambda_{i}}{n_{i}}\right)}, \forall i \in K . \\
& w_{i} \leq s_{i}, \forall i \in K . \\
& n_{i} \in \mathbb{N}, \forall i \in K \\
& w_{i} \geq 0, \forall i \in K
\end{aligned}
$$

\section{Studi Kasus}

Dalam studi kasus, data yang dipakai merupakan data aktual lalu lintas yang diambil dari plaza tol yang potensial pada daerah highway. Tipe jalur yang akan didesain berjumlah 3 yakni, tipe ETC, ACM dan Manual.
Pengelola juga menginginkan jumlah jalur pada plaza tol sebanyak 16 jalur. Pengelola juga memberikan proiritas yang berbeda untuk off-peak hours dan peak hours.

Tabel 1. Rata-rata tingkat kedatangan jumlah kendaraan (per menit)

\begin{tabular}{|c|c|c|c|c|}
\hline Pukul & $\boldsymbol{\lambda}$ & $\boldsymbol{\lambda}_{\mathrm{E}}$ & $\boldsymbol{\lambda}_{\mathrm{A}}$ & $\boldsymbol{\lambda}_{\mathrm{M}}$ \\
\hline $24.00-01.00$ & 16.4 & 3.1 & 4.2 & 9.1 \\
\hline $01.00-02.00$ & 17.1 & 3.5 & 4.3 & 9.3 \\
\hline $02.00-03.00$ & 16.7 & 3.3 & 4.5 & 8.9 \\
\hline $03.00-04.00$ & 21.6 & 4.1 & 5.2 & 12.3 \\
\hline $04.00-05.00$ & 26.3 & 5.7 & 4.9 & 15.7 \\
\hline $05.00-06.00$ & 35.6 & 7.9 & 7.3 & 20.4 \\
\hline $06.00-07.00$ & 71.5 & 21.6 & 17.5 & 32.4 \\
\hline $07.00-08.00$ & 100.7 & 30.4 & 25.1 & 45.2 \\
\hline $08.00-09.00$ & 81.7 & 24.2 & 20.8 & 36.7 \\
\hline $09.00-10.00$ & 63.4 & 18.2 & 18.2 & 27 \\
\hline $10.00-11.00$ & 54.4 & 14.8 & 15.3 & 24.3 \\
\hline $11.00-12.00$ & 49.1 & 12.4 & 13.5 & 23.2 \\
\hline $12.00-13.00$ & 46.8 & 11.5 & 12.6 & 22.7 \\
\hline $13.00-14.00$ & 48.6 & 12 & 13.1 & 23.5 \\
\hline $14.00-15.00$ & 51.8 & 13.2 & 14.4 & 24.2 \\
\hline $15.00-16.00$ & 58 & 15.4 & 16.3 & 26.3 \\
\hline $16.00-17.00$ & 62.9 & 17.2 & 17.7 & 28 \\
\hline $17.00-18.00$ & 69.9 & 19.7 & 18.5 & 31.7 \\
\hline $18.00-19.00$ & 81.5 & 24.1 & 20.6 & 36.8 \\
\hline $19.00-20.00$ & 77.1 & 23.3 & 18.9 & 34.9 \\
\hline $20.00-21.00$ & 65.5 & 20.3 & 14.8 & 30.4 \\
\hline \hline $21.00-22.00$ & 40.2 & 10.9 & 9.2 & 20.1 \\
\hline $22.00-23.00$ & 28.5 & 6.6 & 6.3 & 15.6 \\
\hline $23.00-24.00$ & 19.3 & 3.9 & 5 & 10.4 \\
\hline
\end{tabular}

Tabel 1. memperlihatkan data rata-rata tingkat kedatangan untuk ketiga tipe jalur. Sebagai contoh pada pukul 24.00 - 01.00 rata-rata kedatangan kendaraan pada jalur tipe manual sebanyak 9.1 kendaraan.

Tabel 2. memperlihatkan data jumlah minimum jalur yang harus dibuka untuk ketiga tipe jalur. Sebagai contoh pada pukul 24.00 - 01.00 rata-rata kedatangan kendaraan pada tipe ACM sebanyak 1 jalur. Walaupun jumlah minimum jalur tipe ETC yang harus dibuka adalah 1 namun pada batas bawah jumlah jalur tipe ini harus diberi nilai 2. Hal ini juga berlaku untuk jalur tipe ACM.

Tabel 3. memperlihatkan data tingkat biaya operasional harian dan biaya tunggu-pengguna untuk ketiga tipe jalur. Sebagai contoh pada pukul 24.00 sampai pukul 06.00 biaya harian pada jalur tipe ETC sebesar $\$ 1.5$.

Selanjutnya, diasumsikan bahwa rata-rata jumlah pelayanan (jumlah pelayanan yang tuntas per menit) tidak berubah sepanjang waktu. Rata-rata jumlah pelayanan untuk jalur tipe ETC, ACM dan manual berturut-turut adalah $\mu_{E}=49.8, \mu_{A}=10.2$ dan $\mu_{M}=6.1$ per menit. Sedangkan standar deviasi masing-masing tipe adalah $\sigma_{E}=0.01, \sigma_{A}=0.06$ dan $\sigma_{M}=0.12$. Untuk waktu standar pelayanan $\left(s_{\mathrm{i}}\right)$ ditentukan berdasarkan survey yang dilakukan pengelola pada pengguna jalan tol. Dari hasil 
tersebut ditetapkan bahwa untuk jalur tipe ACM dan manual waktu standar pelayanannya sebesar $s_{A}=s_{M}=0.5$ menit sedangkan untuk jalur tipe ETC sebesar $s_{E}=0.033$ menit.

Tabel 2. Jumlah minimum jalur yang harus dibuka

\begin{tabular}{|c|c|c|c|}
\hline Pukul & $\boldsymbol{b}_{\mathrm{E}}$ & $\boldsymbol{b}_{\mathrm{A}}$ & $\boldsymbol{b}_{\mathrm{M}}$ \\
\hline $24.00-01.00$ & 1 & 1 & 2 \\
\hline $01.00-02.00$ & 1 & 1 & 2 \\
\hline $02.00-03.00$ & 1 & 1 & 2 \\
\hline $03.00-04.00$ & 1 & 1 & 3 \\
\hline $04.00-05.00$ & 1 & 1 & 3 \\
\hline $05.00-06.00$ & 1 & 1 & 4 \\
\hline $06.00-07.00$ & 1 & 2 & 6 \\
\hline $07.00-08.00$ & 1 & 3 & 8 \\
\hline $08.00-09.00$ & 1 & 3 & 7 \\
\hline $09.00-10.00$ & 1 & 2 & 5 \\
\hline $10.00-11.00$ & 1 & 2 & 4 \\
\hline $11.00-12.00$ & 1 & 2 & 4 \\
\hline $12.00-13.00$ & 1 & 2 & 4 \\
\hline $13.00-14.00$ & 1 & 2 & 4 \\
\hline $14.00-15.00$ & 1 & 2 & 4 \\
\hline $15.00-16.00$ & 1 & 2 & 5 \\
\hline $16.00-17.00$ & 1 & 2 & 5 \\
\hline $17.00-18.00$ & 1 & 2 & 6 \\
\hline $18.00-19.00$ & 1 & 3 & 7 \\
\hline $19.00-20.00$ & 1 & 2 & 6 \\
\hline $20.00-21.00$ & 1 & 2 & 5 \\
\hline \hline $21.00-22.00$ & 1 & 1 & 4 \\
\hline $22.00-23.00$ & 1 & 1 & 3 \\
\hline $23.00-24.00$ & 1 & 1 & 2 \\
\hline
\end{tabular}

Tabel 3. Tingkat biaya operasional harian dan biaya tunggu-pengguna (\$/jam)

\begin{tabular}{|c|c|c|c|c|}
\hline Pukul & $\mathbf{d}$ & $\mathbf{c}_{\mathbf{E}}$ & $\mathbf{c}_{\boldsymbol{A}}$ & $\mathbf{c}_{\mathbf{M}}$ \\
\hline $24.00-06.00$ & 10 & 1.5 & 0.7 & 18.75 \\
\hline $06.00-09.00$ & 15 & 1.5 & 0.7 & 12.5 \\
\hline $09.00-17.00$ & 10 & 1.5 & 0.7 & 12.5 \\
\hline $17.00-21.00$ & 15 & 1.5 & 0.7 & 12.5 \\
\hline $21.00-24.00$ & 10 & 1.5 & 0.7 & 16.25 \\
\hline
\end{tabular}

\section{Hasil}

Seluruh data di atas akan dimasukan ke model MINLP untuk dicari solusinya. Solusi yang diinginkan merupakan solusi per jam. Selain itu dari data dapat ditentukan bahwa pada pukul 06.00-09.00 dan pukul 17.00-21.00 merupakan sesi peak hours, sedangkan sisanya adalah sesi off-peak hours.

Berikut ini contoh hasil perhitungan dengan menggunakan model (9) untuk pukul 24.00-01.00. Indeks $\mathrm{i}=1$ menunjukan tipe ETC, $\mathrm{i}=2$ mewakili tipe ACM dan $\mathrm{i}=3$ untuk tipe Manual.
Min

$$
\begin{aligned}
Z= & \left(1.5 n_{1}+10(3.1) w_{1}\right)+ \\
& \left(0.7 n_{2}+10(4.2) w_{2}\right)+ \\
& \left(18.75 n_{3}+10(9.1) w_{3}\right)
\end{aligned}
$$

dengan kendala

$$
\begin{aligned}
& \frac{3.1}{n_{1}} \leq 49.8 ; \frac{4.2}{n_{2}} \leq 10.2 ; \frac{9.1}{n_{3}} \leq 6.1 ; \\
& n_{1} \geq 2 ; n_{2} \geq 2 ; n_{3} \geq 3 ; \\
& n_{1} \leq 16 ; n_{2} \leq 16 ; n_{3} \leq 16 ; \\
& \sum_{k=1}^{3} n_{i} \leq 16 . \\
& w_{1}=\frac{3.1\left((49.8)^{2}(0.01)^{2}+1\right)}{2 n_{i}(49.8)\left(49.8-\frac{3.1}{n_{i}}\right)} ; \\
& w_{2}=\frac{4.2\left((10.2)^{2}(0.06)^{2}+1\right)}{4.2} ; \\
& w_{1} \leq 0.033 ; w_{2} \leq 0.5 ; \quad w_{3} \leq 0.5 ; \\
& n_{i} \in \mathbb{N}, i \in\{1,2,3\} \\
& w_{i} \geq 0, i \in\{1,2,3\} \\
& w_{3}=\frac{9.1\left((6.1)^{2}(0.12)^{2}+1\right)}{2 n_{i}(6.1)\left(6.1-\frac{9.1}{n_{i}}\right)} ;
\end{aligned}
$$

Dengan menggunakan toolbox Matlab yakni fungsi fmincon diperoleh hasil

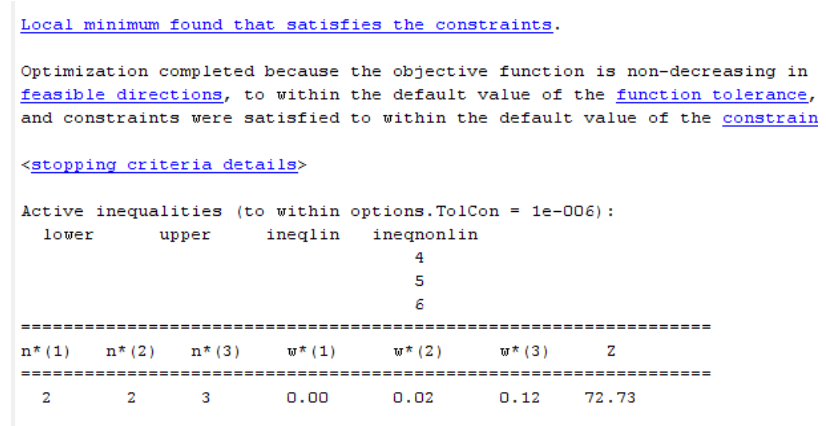

Dari hasil di atas terlihat bahwa jumlah jalur tipe ETC yang harus dibuka adalah 2 jalur, tipe ACM sebanyak 2 jalur dan tipe Manual sebanyak 3 jalur.

Hasil penghitungan secara lengkap solusi optimum untuk 24 jam dapat dilihat pada tabel 4 
Tabel 4. Solusi Optimal (\$/jam)

\begin{tabular}{|c|c|c|c|c|c|c|c|c|c|c|}
\hline Pukul & $\mathbf{n}_{\mathrm{E}}$ & $\mathbf{n}_{\mathrm{A}}$ & $\mathbf{n}_{\mathrm{M}}$ & $w_{E}$ & $\mathrm{w}_{\mathrm{A}}$ & $\mathbf{w}_{\mathrm{M}}$ & $\mathrm{w}$ & $\mathrm{C}_{\mathrm{o}}$ & $C_{w}$ & $\mathbf{Z}$ \\
\hline $24.00-01.00$ & 2 & 2 & 3 & 0 & 0.02 & 0.12 & 72 & 60.65 & 12.08 & 72.73 \\
\hline $01.00-02.00$ & 2 & 2 & 3 & 0 & 0.02 & 0.13 & 77 & 60.65 & 12.89 & 73.54 \\
\hline $02.00-03.00$ & 2 & 2 & 3 & 0 & 0.02 & 0.12 & 69 & 60.65 & 11.48 & 72.13 \\
\hline $03.00-04.00$ & 2 & 2 & 3 & 0.001 & 0.02 & 0.26 & 198 & 32.96 & 93.61 & 93.61 \\
\hline $04.00-05.00$ & 2 & 2 & 4 & 0.001 & 0.02 & 0.23 & 221 & 79.40 & 36.75 & 116.15 \\
\hline $05.00-06.00$ & 2 & 3 & 6 & 0.001 & 0.02 & 0.16 & 204 & 117.60 & 33.97 & 151.57 \\
\hline $06.00-07.00$ & 2 & 4 & 10 & 0.004 & 0.05 & 0.14 & 335 & 130.80 & 83.72 & 214.52 \\
\hline $07.00-08.00$ & 2 & 4 & 10 & 0.006 & 0.11 & 0.36 & 1149 & 130.80 & 287.24 & 418.04 \\
\hline $08.00-09.00$ & 2 & 4 & 10 & 0.004 & 0.07 & 0.19 & 512 & 130.80 & 127.99 & 258.79 \\
\hline $09.00-10.00$ & 2 & 6 & 8 & 0.003 & 0.03 & 0.16 & 287 & 107.20 & 47.80 & 155.00 \\
\hline $10.00-11.00$ & 2 & 6 & 7 & 0.002 & 0.02 & 0.17 & 265 & 94.70 & 44.16 & 138.86 \\
\hline $11.00-12.00$ & 2 & 6 & 7 & 0.002 & 0.02 & 0.15 & 225 & 94.70 & 37.54 & 132.24 \\
\hline $12.00-13.00$ & 2 & 5 & 7 & 0.002 & 0.02 & 0.14 & 212 & 94.00 & 35.41 & 129.41 \\
\hline $13.00-14.00$ & 2 & 5 & 7 & 0.002 & 0.02 & 0.15 & 237 & 94.00 & 39.47 & 133.47 \\
\hline $14.00-15.00$ & 2 & 6 & 7 & 0.002 & 0.02 & 0.16 & 259 & 94.70 & 43.09 & 137.79 \\
\hline $15.00-16.00$ & 2 & 6 & 8 & 0.002 & 0.02 & 0.15 & 258 & 107.20 & 43.04 & 150.24 \\
\hline $16.00-17.00$ & 2 & 6 & 8 & 0.003 & 0.03 & 0.17 & 317 & 107.20 & 52.75 & 159.95 \\
\hline $17.00-18.00$ & 2 & 4 & 10 & 0.003 & 0.06 & 0.14 & 325 & 130.80 & 81.19 & 211.99 \\
\hline $18.00-19.00$ & 2 & 4 & 10 & 0.004 & 0.07 & 0.19 & 513 & 130.80 & 128.35 & 259.15 \\
\hline $19.00-20.00$ & 2 & 4 & 10 & 0.004 & 0.06 & 0.17 & 424 & 130.80 & 105.95 & 236.75 \\
\hline $20.00-21.00$ & 2 & 5 & 9 & 0.003 & 0.03 & 0.16 & 313 & 119.00 & 78.32 & 197.32 \\
\hline $21.00-22.00$ & 2 & 4 & 6 & 0.002 & 0.02 & 0.15 & 197 & 103.30 & 32.80 & 136.10 \\
\hline $22.00-23.00$ & 2 & 3 & 4 & 0.001 & 0.02 & 0.22 & 216 & 70.10 & 35.97 & 106.07 \\
\hline $23.00-24.00$ & 2 & 2 & 3 & 0.001 & 0.02 & 0.17 & 110 & 53.15 & 18.35 & 71.50 \\
\hline
\end{tabular}

\section{KESIMPULAN}

Kombinasi yang tepat dari berbagai tipe jalur agar penggunaan masing-masing jalur optimal bisa meminimumkan waktu tunggu dan biaya operasional tiap jalur. Dalam menyusun kombinasi yang tepat perlu diperhatikan rata-rata waktu tunggu, rata-rata kendaraan yang masuk pada suatu jalur dan off-peak/peak hours. Selain itu, perlu juga diperhatikan sistem antrian dari kendaraan pada jalur tersebut.

\section{DAFTAR PUSTAKA}

Cooper, R. B. (1981). Introduction to Queueing Theory. North-Holland, New York.

Hillier, F. S., dan Lieberman, G. J. (2001). Introduction To Operation Research. McGraw-Hill, New York.

Kim, S. (2009). The Toll Plaza Optimization Problem: Design, Operations, and Strategies. Transportation Research Part E. Vol. 45, hal 125-137.

Osaki,S. (1992). Applied Stochastic System Modelling. Springer-Verlag, Germany.

Wilson, H. B., dkk . (2003). Advanced Mathematics and Mechanics Applications Using Matlab. Chapman \& Hall/CRC, London.

Steele, JH; Fernandez, J. 1991. "History of Rabies and Global Aspects", di dalam Baer, GM, The Natural History of Rabies (edisi ke-2), Boca Raton, Florida: CRC Press, Inc., hlm. 1, ISBN $\underline{0849367603}$

Twisleton-Wykeham-Fiennes, N. 1978. Zoonoses and the Origins and Ecology of Human Disease. Academic Press, London. 